\title{
TRIP-assisted steels: cracking of high-carbon martensite
}

\section{S. Chatterjee and H. K. D. H. Bhadeshia*}

\begin{abstract}
Modern TRIP assisted steels contain retained austenite with carbon concentrations in excess of $1 \mathrm{wt}-\%$. Some of their mechanical properties, in particular the toughness and ductility, rely on the diffusionless transformation of this austenite into high-carbon martensite, induced by stress and strain. The properties can be excellent in spite of the fact that freshly formed high-carbon martensite is brittle. This contradictory behaviour has yet to be explained. In the present paper, the authors propose and show experimentally that the tendency of the martensite to crack in a mixed microstructure of austenite and martensite depends on its absolute size. It is demonstrated that in these mixtures, it is more difficult to crack fine martensite. It is the fine scale of the retained austenite in TRIP assisted steels that permits the martensite to be tolerated without endangering their mechanical properties.
\end{abstract}

Keywords: TRIP-assisted steels, Martensite cracking, Composite, Stress transfer

\section{Introduction}

There are many steels which rely on the stress- or strain induced martensitic transformation of retained austenite to achieve properties. ${ }^{1-17}$ The most successful of these use only small concentrations of alloying elements but manage nevertheless to retain austenite. They do so by exploiting the fact that carbon is partitioned into the residual austenite following the growth of bainitic ferrite and the carbon remains there when cementite precipitation is prevented by the judicious use of elements such as silicon or aluminium. The retained austenite can routinely end up with carbon concentrations in excess of $1 \mathrm{wt}-\%$.

The alloys include the transformation induced plasticity (TRIP) assisted steels reputed for their strength and formability, ${ }^{2-7}$ wear and fatigue resistant rail steels, ${ }^{10,11}$ and extremely strong steels for protection against ballistic impact. ${ }^{12-17}$ The alloys all rely on the stressand strain induced transformation of the austenite into martensite to optimise performance.

The properties achieved to date are impressive and yet surprising because the martensite inherits the very high carbon concentration of the parent austenite. Untempered, high-carbon martensite is known to be very brittle - this does not reconcile with the observed formability of these TRIP-assisted steels. The purpose of the present paper is to explain why this apparently brittle martensite is not in fact a liability.

\section{Hypothesis}

A striking feature of well designed TRIP-assisted steels is that the martensite does not crack even at large plastic

University of Cambridge, Materials Science and Metallurgy, Pembroke Street, Cambridge CB2 3QZ, UK

*Corresponding author, email hkdb@cus.cam.ac.uk strains. At the same time, it has been demonstrated that the properties are worst when any islands of martensite that form are coarse. ${ }^{8,9}$

A similar phenomenon is observed in uniaxially aligned, discontinuous, brittle fibre composites. ${ }^{18,19}$ Axial stress is transmitted from the matrix into the fibre via shear loading of the cylindrical surface of the fibre. This load transfer causes the tensile stress in the latter to rise to a maximum value $\sigma_{\mathrm{P}}$ half way along the length of the fibre. If $\sigma_{\mathrm{P}}$ exceeds the fracture strength $\sigma_{\mathrm{F}}$, the fibre breaks. However if the fibre is short, end effects prevent the maximum stress in the fibre from reaching $\sigma_{\mathrm{F}}$. The fibre then remains intact. The critical fibre length below which it does not fracture is designated $l_{\mathrm{C}}$. Fibres longer than $l_{\mathrm{C}}$ tend to break into segments of length $l_{\mathrm{C}}$.

It is proposed here that load transfer into the hard martensite becomes similarly difficult as the scale of the martensite in a relatively soft matrix decreases. In other words, the martensite will not crack easily if its size is reduced below some critical value. Naturally, work hardening comes into this scenario so that sufficient load should eventually be transferred into the martensite to cause fracture. However, the stage at which this occurs ought to be delayed when the martensite is fine.

With this in mind, experiments were designed to study the cracking tendency of brittle martensite, in a mixed microstructure of austenite and martensite (to reflect the composite character of the fibre model), as a function of its scale.

\section{Experimental}

The aim of the experiments was to observe microcracking in martensite plates of different sizes, the cracking being induced by quench stresses; the plate length was varied by altering the austenite grain size. A steel with the composition of $\mathrm{Fe}-0 \cdot 98 \mathrm{C}-1 \cdot 46 \mathrm{Si}-1 \cdot 89 \mathrm{Mn}-1 \cdot 26 \mathrm{Cr}-$ $0 \cdot 26 \mathrm{Mo}$ (wt- $\%$ ) was selected for the present study. Its 


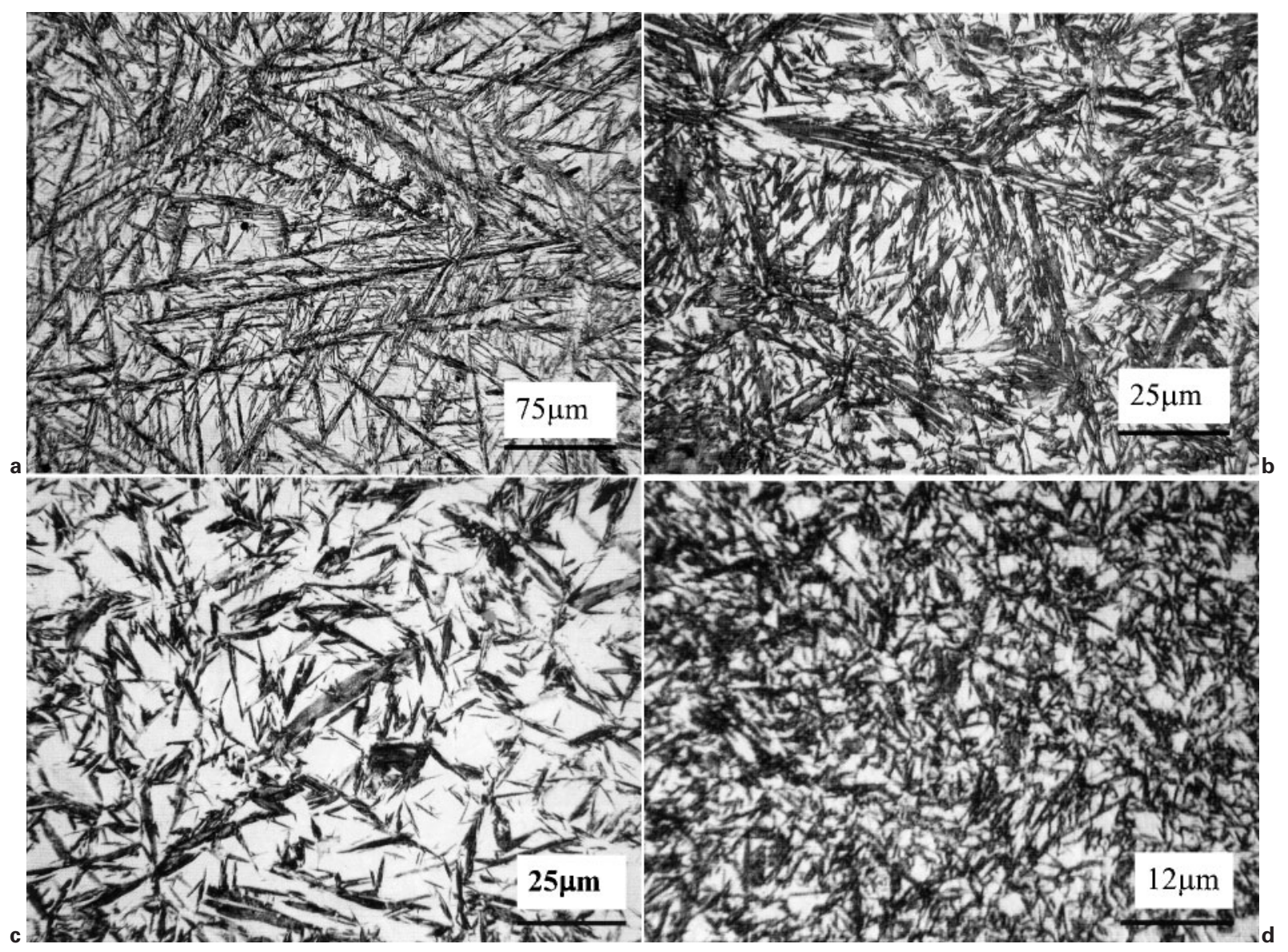

1 Optical micrographs of specimens quenched from a 1200, b 1100, $c 1000$ and $d 950^{\circ} \mathrm{C}$ : note that micrographs are presented at different magnifications for clarity

carbon concentration is representative of the retained austenite found in TRIP assisted steels. Cylindrical specimens of $12 \mathrm{~cm}$ length and $8 \mathrm{~cm}$ diameter were made out of this steel and sealed in quartz tubes containing a partial pressure of argon for heat treatment in an air furnace.

The sealed specimens were austenitised at 1200, 1100, 1000 and $950^{\circ} \mathrm{C}$ for $10 \mathrm{~min}$ in order to generate a range of austenite grain sizes for subsequent transformation into martensite during quenching in water. It was very difficult to etch in a manner which reveals the austenite grain boundaries. Therefore, another set of specimens was cooled slowly by switching off the furnace following the same austenitising conditions; this was performed in order to obtain a clear definition of the austenite grain boundaries. To rule out any intrinsic effect of austenitisation temperature, one specimen was heated to $1200^{\circ} \mathrm{C}$ for 10 min followed by soaking at $950^{\circ} \mathrm{C}$ for another $10 \mathrm{~min}$ before finally quenching to room temperature.

Cross-sections of the quenched specimens were polished using standard metallographic techniques. They were examined in their unetched states using optical microscopy to characterise any cracks. The specimens were then etched using $10 \mathrm{wt}-\%$ aqueous sodium metabisulphite solution for further observations. The martensite plate lengths were measured using a graticule fitted to the microscope. These of course are apparent lengths because the observations are performed on two-dimensional sections. The furnace cooled specimens were etched with boiling picral solution to reveal the austenite grain size as a function of the austenitising temperature; the size was characterised using the lineal intercept $\bar{L}$ method.

\section{Results}

Optical micrographs of specimens quenched after heating at different austenitising temperatures $T_{\gamma}$ showed, as expected, dark etching martensite plates embedded in a matrix of retained austenite (Fig. 1). The plates naturally become finer as the austenite grain size $\bar{L}_{\gamma}$ is reduced.

The heat treatments used achieved the desired variation in the austenite grain size, as shown in Table 1.

Microcracks were clearly visible in the large $\bar{L}_{\gamma}$ specimens austenitised at 1200 and $1100^{\circ} \mathrm{C}$, which contained the coarsest martensite plates (Fig. 2). The cracks propagate across the plates and the largest of the plates appeared to be periodically cracked (as expected

\begin{tabular}{rcc} 
Table 1 & $\begin{array}{c}\text { Austenite } \\
\text { austenitisation temperature }\end{array}$ & $\begin{array}{c}\text { grain } \\
\text { size }\end{array}$ \\
\hline $\boldsymbol{T}_{\gamma},{ }^{\circ} \mathbf{C}$ & $\bar{L}_{\gamma}, \mu \mathrm{m}$ & Error, $\mu \mathrm{m}$ \\
\hline 1200 & 410 & 53 \\
1100 & 124 & 25 \\
1000 & 65 & 12 \\
950 & 25 & 7 \\
\hline
\end{tabular}

The measurements were performed on the slowly cooled specimens where the austenite grain structure is more easily seen. The error represents $\pm 1 \sigma$. 


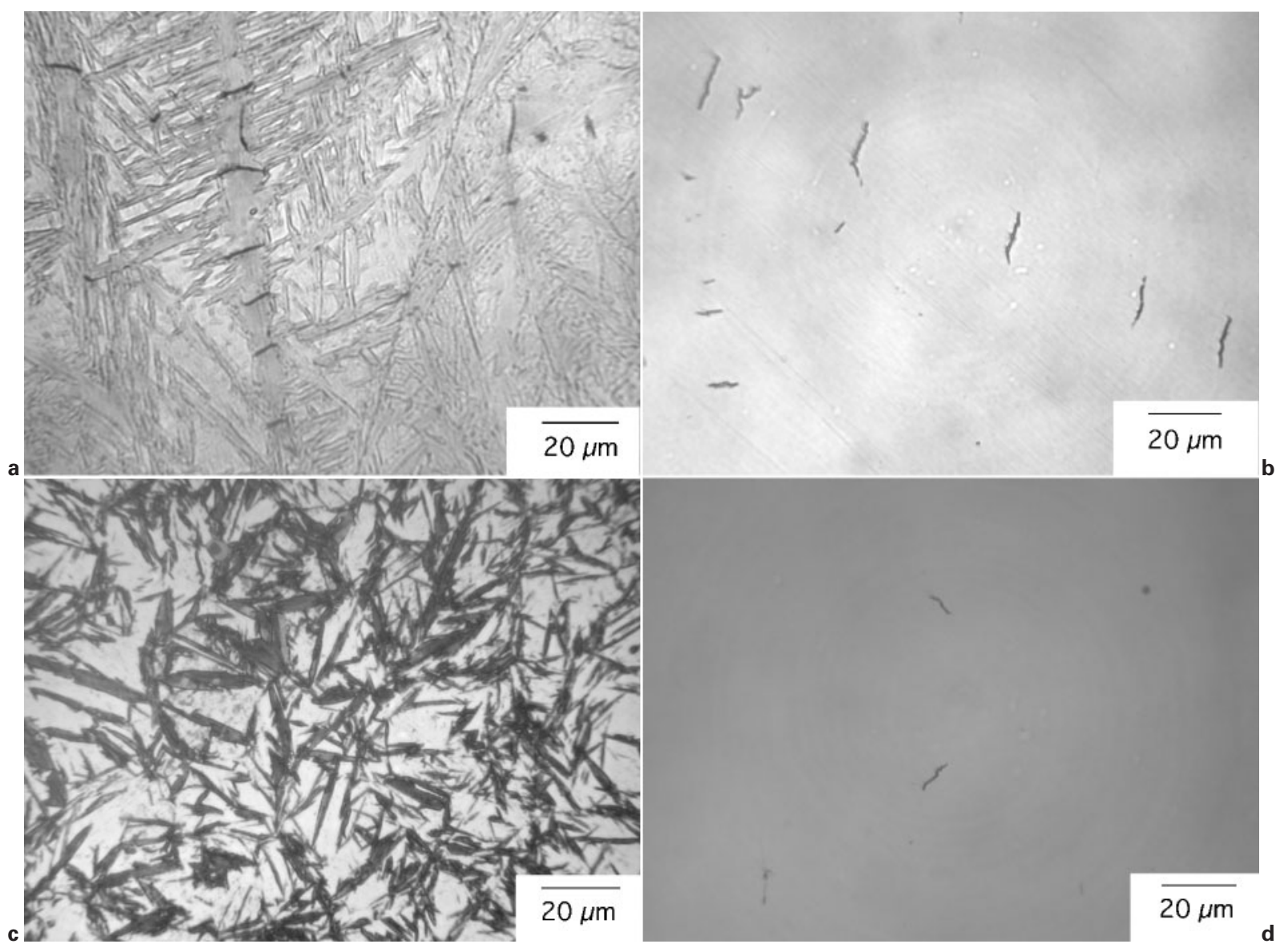

2 Microcracking in specimen austenitised at $1200^{\circ} \mathrm{C}$ : $a$ etched specimen and $b$ periodically cracked plate in unetched specimen; corresponding images for $T_{\gamma}=1000^{\circ} \mathrm{C}$ of $c$ etched specimen where cracks are difficult to observe and $d$ occasional cracks visible in unetched specimen

from the fibre loading model). The coarse plates are the first to form and their growth is restricted only by the austenite grain surfaces. Subsequent plates are finer because they grow in the geometrically partitioned, untransformed regions of residual austenite; they are restricted not only by the austenite grain boundaries but also by the presence of previously formed martensite. The result is finer plates in which there appeared to be a smaller tendency to crack. There were very few cracks visible in the martensite plates of the $T_{\gamma}=1000^{\circ} \mathrm{C}$ specimen and each plate in general was only singly cracked. The $T_{\gamma}=950^{\circ} \mathrm{C}$ specimen was found to be free of any cracks visible in the optical microscope.

It is possible that quenching the specimens described above into water from different temperatures could have affected the observations. For this reason, one specimen was austenitised at $1200^{\circ} \mathrm{C}$, then transferred into a furnace at $950^{\circ} \mathrm{C}$ and held there for $10 \mathrm{~min}$ before quenching in water. There was no apparent reduction in the tendency for cracking when compared with the specimen quenched directly from $1200^{\circ} \mathrm{C}$; a typical micrograph from the step quenched specimen is illustrated in Fig. 3.

\section{Crack spacings}

The distance between adjacent cracks in individual fragmented plates of martensite were measured using optical metallography. These distances are designated $l_{\mathrm{a}}$ to emphasise that they are apparent measures because stereological effects are not taken into account. The data from the coarse grained specimens austenitised at 1200 and $1100^{\circ} \mathrm{C}$ are illustrated in Fig. 4; for these cases, the mean values of $\bar{l}_{\mathrm{a}}$ were found to be 58 and $38 \mu \mathrm{m}$ respectively. More relevant is the minimum value observed in all the measurements, which is within experimental error found to be $\sim 10 \mu \mathrm{m}$.

If it is assumed that the critical stress transfer length $l_{\mathrm{C}}=10 \mu \mathrm{m}$, an austenite grain size which is somewhat less than this value would avoid quench cracking of the type explored in the present paper. One difficulty is that

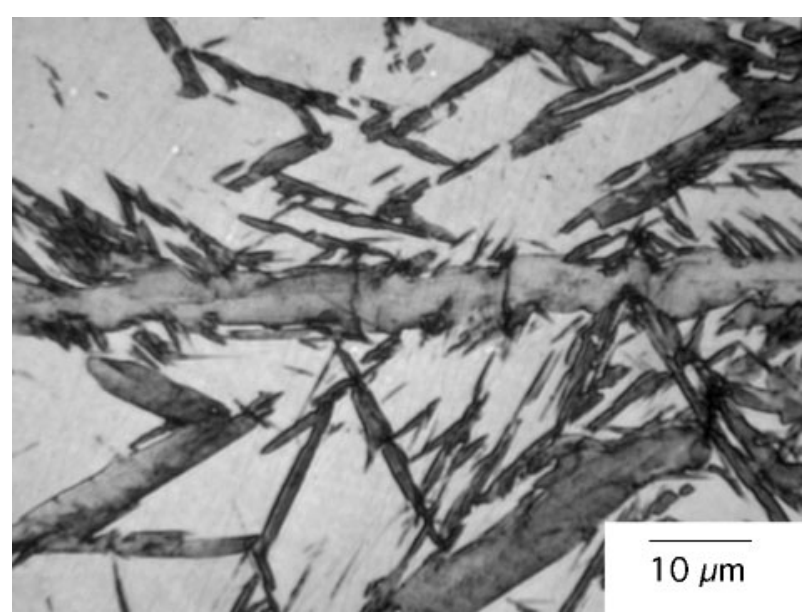

3 Microcracking in specimen austenitised at $1200^{\circ} \mathrm{C}$ and soaked at $950^{\circ} \mathrm{C}$ before quenching 

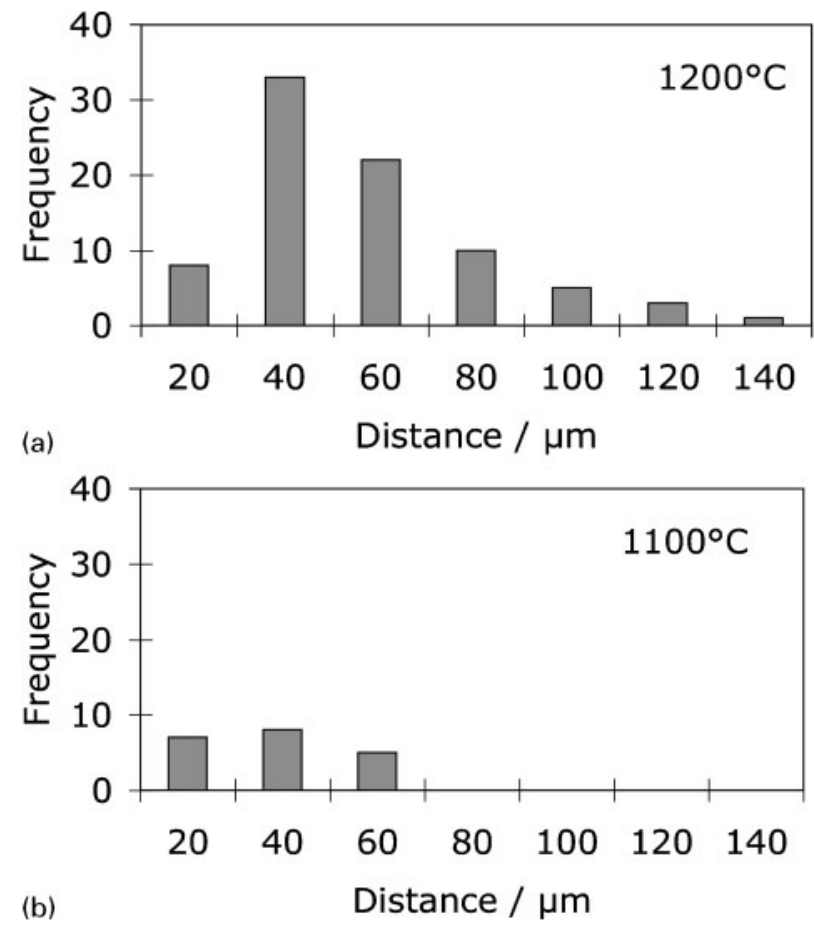

a $T_{\gamma}=1200^{\circ} \mathrm{C} ; b T_{\gamma}=1100^{\circ} \mathrm{C}$

4 Frequency of observation $v$. apparent distance between cracks on individual martensite plates in specimens with coarsest microstructures

we have not been able to observe cracks in the $T_{\gamma}=950^{\circ} \mathrm{C}$ specimen with a grain size of $25 \mu \mathrm{m}$, which is greater than $l_{\mathrm{C}}$. It is possible that the cracks exist but have been missed because the specimen contains few plates of length greater than $l_{\mathrm{C}}$. Therefore, plate length distributions were measured as described in the next section.

\section{Plate lengths}

The apparent lengths of approximately 180 martensite plates from each specimen were measured using optical metallography. In all cases, the plates were chosen at random by arbitrarily translating the stage across a cursor which identified the plate to be measured. The size distributions are illustrated in Fig. 5, plotted on identical scales to facilitate comparisons.

It is evident that a coarse grain size tends to have a more uniform distribution of plate sizes (Fig. 5a) whereas the smallest plates dominate when the austenite grain size is reduced (Fig. 5d). This is consistent with the work by Guimarães and co-workers on the heterogeneity of martensitic transformation when the austenite grain size is small. ${ }^{20,21}$ Some austenite grains transform via a burst of martensite while others remain fully austenitic. Such bursts can be expected to lead to a greater preponderance of fine plates. By contrast, coarse grained microstructures transform uniformly with the majority of austenite grains participating, therefore allowing a gradual evolution of microstructure as the specimen is cooled. This should lead to a more uniform distribution of plate sizes as is noticeable in Fig. $5 a$.

Because the longest plates grow first, it is assumed that the measured plate lengths can be sorted into a descending size array which represents the order in which the plates nucleated. The measured lengths are plotted in Fig. $6 a$ after sorting in the manner described; the horizontal axis could be assumed to represent time
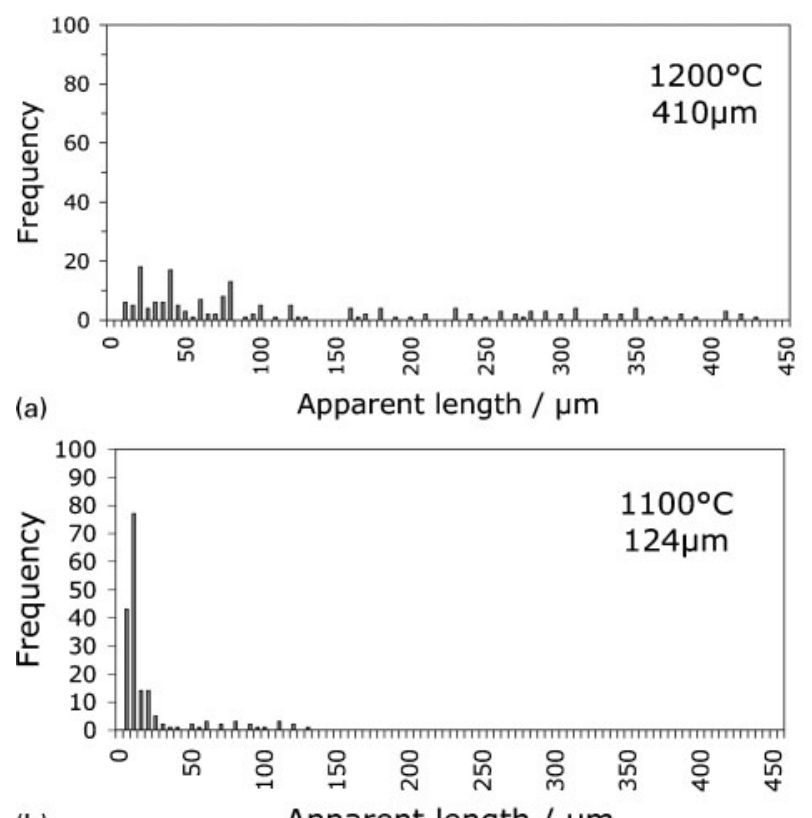

(b) Apparent length / $\mu \mathrm{m}$

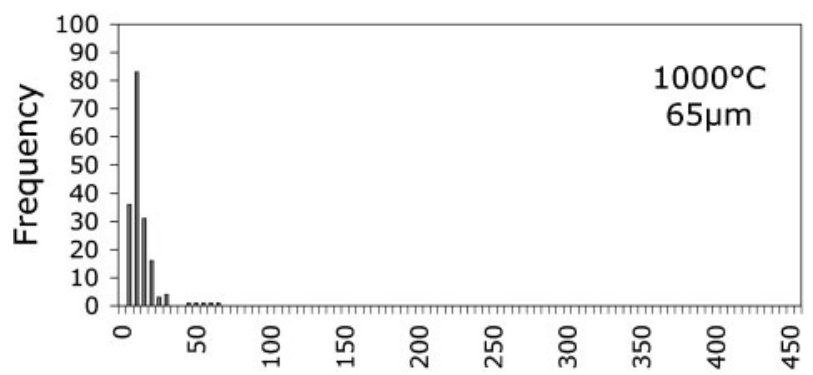

(c)

Apparent length / $\mu \mathrm{m}$

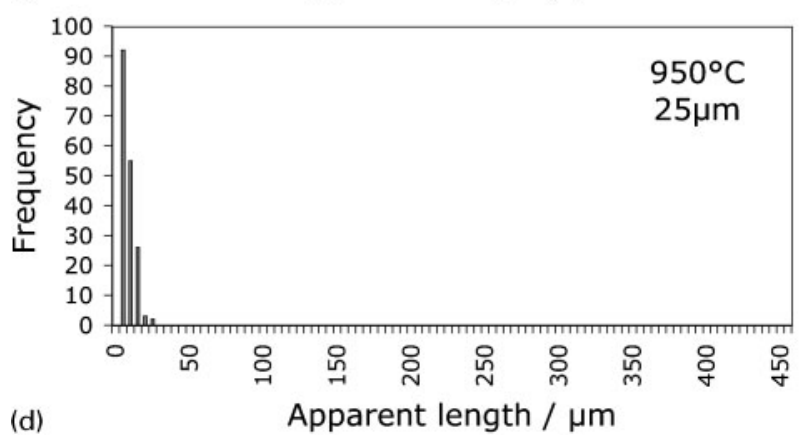

5 Distribution of apparent martensite plate lengths ( $\boldsymbol{T}_{\gamma}$ and $\bar{L}_{\gamma}$ values stated): distributions are all on same scale to allow comparisons to be made; bin size on horizontal scale is $5 \mu \mathrm{m}$

as the specimen cools, or undercooling below the martensite start temperature.

An attempt was made to understand the illustrated behaviour using a simple notion that each plate subdivides the austenite region in which it forms. Therefore, the volume $V_{\mathrm{n}}$ of untransformed austenite regions after $n=1,2,3, \ldots$ subdivisions have occurred is

$$
V_{\mathrm{n}}=\frac{V_{0}}{2^{\mathrm{n}-1}}
$$

where $V_{0}$ is the starting volume of an austenite grain. If all austenite grains and their subdivisions can be regarded as truncated octahedra, the mean lineal intercept is related to the volume by ${ }^{22}$

$$
\bar{L}_{\gamma}=\left(0 \cdot 4266 V_{\mathrm{n}}\right)^{1 / 3}
$$



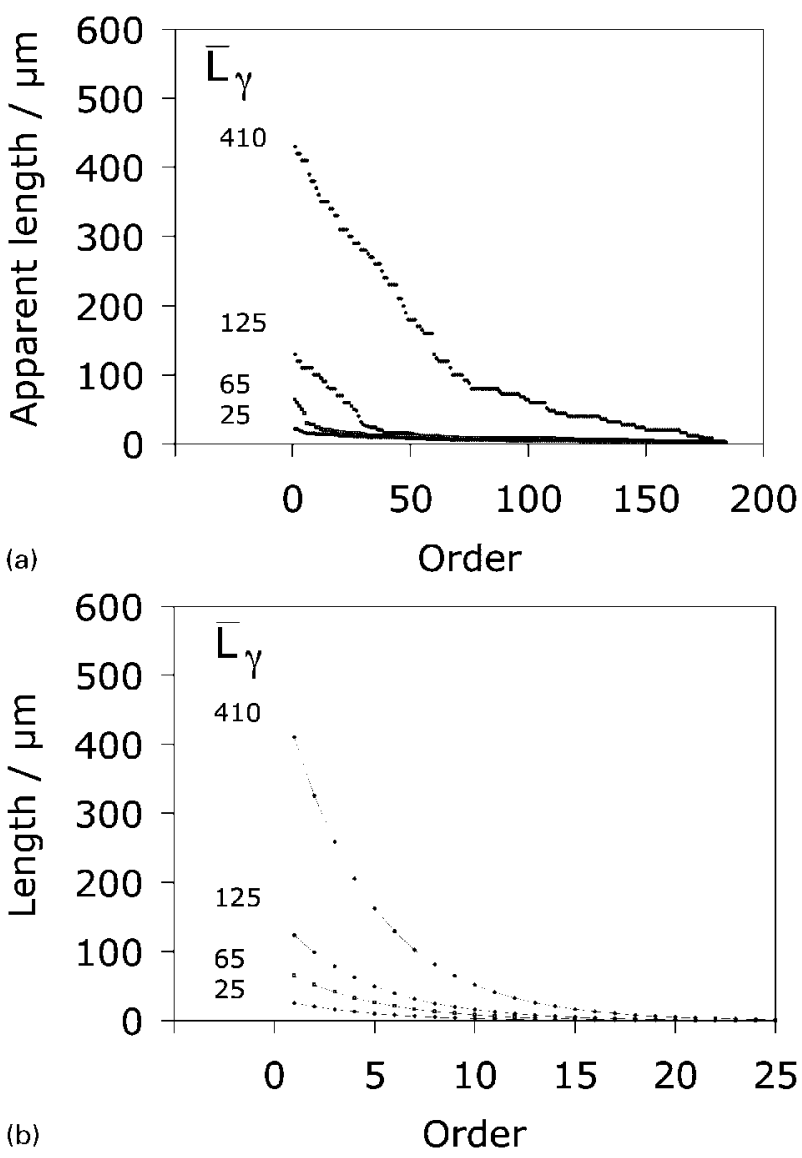

6 a experimentally measured apparent lengths of martensite plates arranged in sequence in which they are assumed to form and $b$ corresponding curves for calculated length $v$. order in which plates form

this allows $V_{0}$ to be calculated using the data listed in Table 1 . Furthermore, the value of $\bar{L}_{\gamma}$ at any stage of transformation can be taken to represent the maximum length of martensite plate that can form. It follows that the plate length can be calculated as a function of the sequence $n$ as illustrated in Fig. $6 b$.

The calculated and measured curves in Fig. 6 compare well in terms of the influence of the initial austenite grain size and with respect to their general shapes. However, the absolute reduction in length is much greater with the calculated curves. This is because equation (1) implies that the number of plates $N$ that form in each generation $n$ is given by $N=a^{\text {n-1 }}$ with $a=2$. This leads to a rapid increase in $N$ and a correspondingly rapid decrease in the plate length as $n$ increases. Therefore, whereas each point in the calculated curve can represent $N$ plates of identical length, every point in the measured curve is a different plate. The gradual variation in plate length implies that $a<2$; the data indicate a value closer to unity. This can be demonstrated by plotting the logarithm of the measured lengths versus $n$, which for the four different grain sizes gives $a=1 \cdot 01 \rightarrow 1 \cdot 03$.

\section{Summary}

Many modern steels are designed to contain a fraction of finely divided retained austenite in a ferrite rich microstructure. To minimise cost, this austenite is stabilised by suppressing the precipitation of cementite; the carbon partitioned from ferrite, then enriches the austenite, allowing it to be retained to ambient temperature.

This high-carbon austenite can enhance properties when it transforms into fresh martensite as the steel is stressed or strained. The present work suggests that the reason why the untempered, hard martensite does not readily crack is because it is small. This makes it difficult to transfer load onto the martensite when the composite mixture is strained.

It has also been demonstrated that there is a greater tendency to form long plates of martensite, which are most prone to cracking when the austenite grain size is coarse.

\section{Acknowledgments}

The authors are grateful to Tata Steel (India) for supporting the present work and to the University of Cambridge for the provision of laboratory facilities.

\section{References}

1. W. W. Gerberich, G. Thomas, E. R. Parker and V. F. Zackay: Proc. 2nd Int. Conf. on 'Strength of metals and alloys', Vol. 3, 894-899; 1970, Metals Park, OH, American Society for Metals.

2. M. Sudo, M. Higashi, H. Hori, T. Iwai, S. Kame and Z. Shibata: Trans. ISIJ, 1981, 21, 820-827.

3. B. C. de Cooman: Curr. Opin. Sol. State Mater. Sci., 2004, 8, 285303.

4. P. J. Jacques: Curr. Opin. Sol. State Mater. Sci., 2004, 8, 259-265.

5. I. B. Timokhina, E. V. Pereloma and P. D. Hodgson: Mater. Sci. Technol., 2001, 17, 135-140.

6. M. De Meyer, J. Mahieu and B. C. de Cooman: Mater. Sci. Technol., 2002, 18, 1121-1132.

7. S. Papaefthymiou, W. Bleck, S. Kruijver, J. Sietsma, L. Zhao and S. van der Zwaag: Mater. Sci. Technol., 2004, 20, 201-206.

8. H. K. D. H. Bhadeshia and D. V. Edmonds: Met. Sci., 1983, 17, $411-419$.

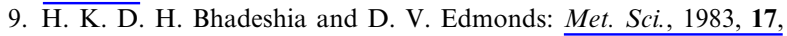
$420-425$.

10. J. K. Yates: Sci. Parl., 1996, 53, 2-3.

11. H. K. D. H. Bhadeshia: in 'Encyclopaedia of materials: science and technology', 1-7; 2002, London, Elsevier Science Ltd.

12. F. G. Caballero, H. K. D. H. Bhadeshia, K. J. A. Mawella, D. G. Jones and P. Brown: Mater. Sci. Technol., 2002, 18, 279284.

13. C. Garcia-Mateo, F. G. Caballero and H. K. D. H. Bhadeshia: J. Phys. Coll., 2003, 112, 285-288.

14. C. Garcia-Mateo, F. G. Caballero and H. K. D. H. Bhadeshia: ISIJ Int., 2003, 43, 1238-1243.

15. C. Garcia-Mateo, F. G. Caballero and H. K. D. H. Bhadeshia: ISIJ Int., 2003, 43, 1821-1825.

16. M. Peet, S. S. Babu, M. K. Miller and H. K. D. H. Bhadeshia: Scr. Mater., 2004, 50, 1277-1281.

17. F. G. Caballero and H. K. D. H. Bhadeshia: Curr. Opin. Sol. State Mater. Sci., 2004, 8, 251-257.

18. H. L. Cox: Brit. J. Appl. Phys., 1952, 3, 72-79.

19. T. W. Clyne and P. J. Withers: in 'An introduction to metal matrix composites', 20; 1993, Cambridge, Cambridge University Press.

20. J. R. C. Guimarães and J. C. Gomes: Acta Metall., 1978, 26, 15911596.

21. J. R. C. Guimarães and A. Saavedra: Mater. Sci. Eng., 1984, 62, 11-15.

22. C. Mack: Proc. Camb. Philos. Soc., 1956, 52, 286. 